\title{
Barriers to and factors facilitating breast cancer screening among Iranian women: a qualitative study
}

M. Lamyian ${ }^{1}$, A. Hydarnia, ${ }^{1}$ F. Ahmadi, ${ }^{2}$ S. Faghihzadeh ${ }^{3}$ and M.E. Aguilar-Vafaie ${ }^{4}$

$$
\begin{aligned}
& \text { العو امل الميسِّرة والمعيقة لثحرِي سر طان الثدي للدى الإير انيات: دراسة كيفية }
\end{aligned}
$$

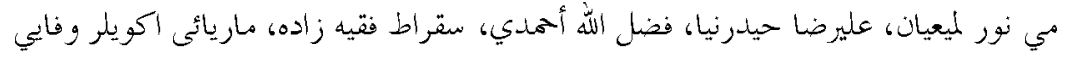

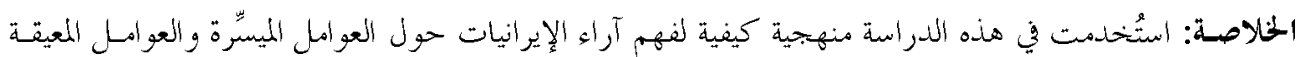

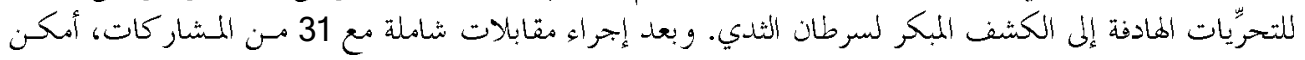

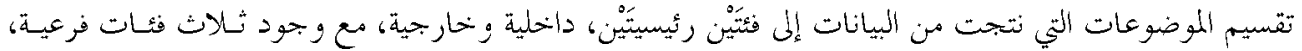

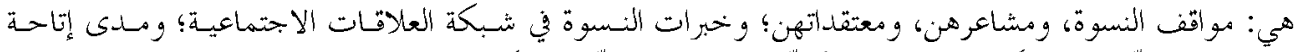

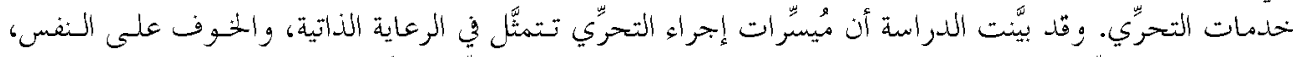

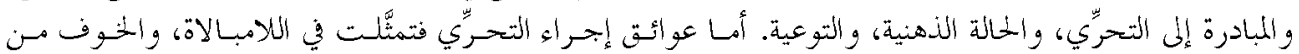

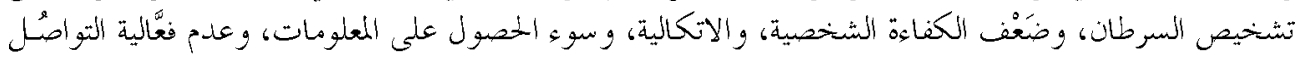

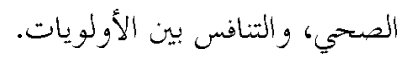

ABSTRACT This study used qualitative methodology to understand Iranian women's views about barriers to and factors facilitating screening for early detection of breast cancer. Using grounded theory with in-depth interviews of 31 participants, themes emerged from the data in 2 main categories (internal and external) with 3 sub-categories: women's attitudes, feelings and beliefs; women's social network experiences; and accessibility. Facilitating factors for screening were self-care, fear, proactive coping, state of mind and advocacy. Barriers were negligence, cancer-related fear, low self-efficacy, fatalism, misinformation, ineffective health communication and competing priorities.

Facteurs inhibiteurs et facilitateurs du dépistage du cancer du sein chez la femme iranienne : étude qualitative

RÉSUMÉ Cette étude a fait appel à la méthode qualitative pour comprendre le point de vue des femmes iraniennes sur les facteurs inhibiteurs et facilitateurs du dépistage précoce du cancer du sein. La grounded theory, ou approche inductive systématique, reposant sur un entretien approfondi avec chacune des 31 participantes a permis l'émergence de thèmes dans 2 grandes catégories (facteurs internes et externes) avec 3 sous-catégories, à savoir attitudes, sentiments et convictions des femmes, expérience des réseaux sociaux féminins et accessibilité. Figuraient parmi les facteurs facilitateurs du dépistage les autosoins, la crainte, le coping (capacité de faire face aux situations) proactif, l'état d'esprit et le soutien; les obstacles au dépistage étaient la négligence, la crainte du cancer, une auto-efficacité médiocre, le fatalisme, la mésinformation, l'inefficacité de la communication en matière de santé et l'existence de priorités concurrentielles.

${ }^{1}$ Faculty of Medical Science, Department of Health Education; ${ }^{2}$ Department of Nursing; ${ }^{3}$ Department of Biostatistics; ${ }^{4}$ Department of Psychology, Tarbiat Modares University, Tehran, Islamic Republic of Iran (Correspondence to A. Hydarnia: hydarnia@modares.ac.ir).

Received: 23/06/05; accepted: 22/08/05 


\section{Introduction}

Breast cancer is the most common cancer among women worldwide. According to the International Agency for Research on Cancer database, there were over 1000000 new cases in the world in the year 2004; furthermore, the rates in women living in developing countries are rising [1]. Finding breast cancer as early as possible greatly improves the likelihood that treatment will be successful. There is no question that early detection could save many thousands of lives each year if more women and their health care providers took advantage of screening tests [2].

In the Islamic Republic of Iran breast cancer ranks as the first cancer among women, comprising $21.4 \%$ of all cancer malignancies among Iranian females [3] and affects women at least one decade earlier than their counterparts in developed countries [4]. Although the prevailing literature indicates that breast cancer in women under 40 years and especially under 30 years is uncommon [5], in one Iranian study, 23\% of breast cancer was observed in women younger than 40 years, many of whom $(70 \%)$ died within a short period of time because of advanced disease at presentation [6]. In Tehran, the capital city, breast cancer is the most common cancer among women ( $25.5 \%$ of the total) with a crude incidence rate of 22.4 per 100000 [7].

A continued increase in the incidence of breast cancer death among Iranian women is due, in part, to low screening rates and late detection of breast cancer [8]. Efforts directed at increasing the early breast cancer detection rate in women are important in order to decrease the burden due to cancer death in this population. Although empirical evidence suggests that use of screening in routine medical care helps reduce cancer deaths and improve survival rates [9], there is some evidence that Iranian women are less likely to have early detection $[4,6]$.
For example, Montazeri's study showed that 1 in 4 women with breast cancer in the Islamic Republic of Iran present late [6].

There is limited information about the beliefs and attitudes of Iranian women concerning breast cancer screening. This study was an attempt to identify the barriers to and factors facilitating early detection of breast cancer among Iranian women, as part of a more comprehensive study of the factors motivating Iranian women's participation in cancer screening (for the first author's $\mathrm{PhD}$ dissertation). We used qualitative methodology as it is particularly well-suited to an exploratory study and for generating hypotheses and models of human behaviour [10]. It is hoped that the findings of this research will be useful for health administrators, health providers and educators to consider when designing strategies and educational practices in cancer prevention.

\section{Methods}

A qualitative study was conducted using individual interviews with women in a grounded theory approach. The term grounded theory reflects the concept that theory emerging from this type of work is grounded in the data [11]. Since recognition of facilitating factors and barriers is the first step in persuading women to make better decisions about preventive and protective care, this study focused on the experiences, views and perceptions of Iranian women about breast cancer screening. The data were collected and analysed during a 6month period in 2004-05.

\section{Participants and data collection}

The participants for the study were selected initially using purposive sampling and then with theoretical sampling according to the codes and categories that emerged from the interviews. Sampling started from a 
municipal culture house (Misagh) and the Iranian Centre for Breast Cancer and then was extended to the participants' home or workplace. The criteria for selection were women aged 40 years and older (the age recommended for screening by most cancer control programmes). The aim of qualitative research is not to randomly select individuals in order to manipulate, control and generalize findings, but to gain a greater understanding of the phenomena [11].

Data collection began with women who were housekeepers. After interviewing 26 women and coding the transcripts, the codes and categories that emerged were related to internal and external variables which led to the decision to interview several other key informants. Other key informants used were health providers, doctors, midwives and nurses. The final participants were 31 women residing in Tehran, of different socioeconomic status, educational level, age, occupation and marital status: 14 housekeepers, 11 women employed outside the home, 2 community health workers (behvarz), 1 doctor, 1 nurse and 1 midwife. The demographic characteristics of the participants are presented in Table 1.

\section{Interviews}

The main researcher contacted each of the potential participants to explain the research objectives. If the participant agreed to take part in the research, an interview was scheduled. Based on the participant's request, interviews were carried out at the woman's home or workplace. Individual semi-structured interviews were conducted in a private place. The interview guide was initially developed with the help of expert peers and consisted of some open-ended questions to allow respondents to explain their own views and experiences as fully as possible.

At the beginning of each interview, the participants were asked about their concept

\begin{tabular}{lc}
\hline $\begin{array}{l}\text { Table } 1 \text { Individual characteristics of the } \\
\text { participants }\end{array}$ & $\begin{array}{c}\text { \% of women } \\
(\boldsymbol{n}=\mathbf{3 1})\end{array}$ \\
\hline Variable & $46.0(6.1)$ \\
\hline Age (years) & 40.4 \\
$\quad$ Mean (SD) & \\
Median & 87.1 \\
Marital status & 12.9 \\
$\quad$ Married & \\
Single/divorced/widowed & 19.3 \\
Education & 64.5 \\
$\quad$ Primary school & 16.2 \\
$\quad$ School diploma & \\
$\quad$ Higher education & \\
Occupation & \\
$\quad$ Housekeeper & \\
$\quad$ Employed outside home & 54.8 \\
Religion & \\
$\quad$ Muslim & \\
\hline SD $=$ standard deviation.
\end{tabular}

of cancer, and what they understood by prevention, risk and early detection; and then to explain their own experiences and perceptions about factors affecting their attendance at screening. For example, they were asked: "In your view, what is the meaning of cancer?" or "What factors facilitate or inhibit active breast cancer screening behaviour?" and "Explain some of your experiences in which you have made decisions which you think were risky". During the interviews, notes were made about the topics raised by the woman and these were raised later if participants had not already spontaneously responded.

Some of these topics helped the researchers to develop an interview guide over time. The interviews were carried out by the same interviewer and were tape-recorded. Then, these records were transcribed verbatim and analysed consecutively. Every interview took 1-3 sessions depending on the tolerance and interest of the participants in 
explaining their own experiences. The duration of each session was between 30 and 180 minutes, with an average of 1.5 hours.

\section{Qualitative analysis}

Data from the interviews were analysed concurrently using the constant comparative method. Open, axial and selective coding was applied to the data. During open coding, the transcript of each interview was reviewed multiple times and the data reduced to codes. The codes that were found to be conceptually similar in nature or related in meaning were grouped into categories. Codes and categories from each interview were compared with codes and categories from other interviews for common links. Interviewing stopped when data saturation occurred. Saturation refers to the repetition of discovered information and confirmation of previously collected data. Data were considered "saturated" when no more codes could be identified and the category was "coherent" or made sense [10].

\section{Validity}

The conformability and credibility of the data were established in 3 main ways: (i) participant's revision, (ii) in-depth prolonged engagement with participants and (iii) faculty member's revisions. The participants were contacted after the analysis and were given a full transcript of their coded interviews with a summary of the emergent themes to determine whether the codes and themes were true to their point of view (member check). As a further validity check, faculty members checked about half of all transcripts (peer check). The results were also checked with some women who did not participate in the research and they confirmed the aptness of the results as well. The researcher documented the steps followed in the research and the decisions made to save the auditability for other researchers to perform the steps of the research in future studies.

\section{Ethical considerations}

The scientific research committee of Tarbiat Modares University approved the research. The ethical procedures for the study assured the confidentiality and autonomy of the participants. All participants were informed of the purpose and design of the study and the voluntary nature of their participation. Consent was sought from the participants for the audiotaping of interviews.

\section{Results}

Qualitative analysis of data revealed 3 major factors affecting women's behaviour concerning breast cancer screening: (i) attitudes, beliefs and feelings, (ii) social network experiences and (iii) accessibility of services (Table 2). The themes underlying each of these categories were further subdivided into internal or external factors. Internal factors were defined as factors that reflect a women's desire or motivation to seek screening for breast cancer, while external factors were factors that reflect a participant's ability to seek cancer screening.

\section{Internal factors}

Attitudes, beliefs and feelings as

facilitating factors

Women's attitudes, beliefs and feelings emerged from the data as important facilitating factors of screening behaviour in 4 main themes: self-care (personal health, cancer history, life status), fear (perceived severity, perceived symptoms, reassurance about pain, seeking reassurance about health), proactive coping (wanting to care for one's self, cancer consequences) and state of mind (spiritual values, optimism). The participant wanted to care because of 


\begin{tabular}{|c|c|c|}
\hline Category & Facilitating factors (subcategories) & Barriers (subcategories) \\
\hline $\begin{array}{l}\text { Attitudes, feelings } \\
\text { and beliefs }\end{array}$ & $\begin{array}{l}\text { - Self-care (personal health, cancer } \\
\text { history, life status) } \\
\text { - Fear (perceived severity, perceived } \\
\text { symptoms, reassurance about } \\
\text { pain, seeking reassurance } \\
\text { about health) } \\
\text { - Proactive coping (wanting to care } \\
\text { for oneself, consequences of } \\
\text { cancer) } \\
\text { - State of mind (spiritual values, } \\
\text { optimism) }\end{array}$ & $\begin{array}{l}\text { - Negligence (perception of good } \\
\text { health, not needing the test, } \\
\text { absence of symptoms) } \\
\text { - Cancer-related fear (fear of cancer } \\
\text { diagnosis, pain, radiation, death) } \\
\text { - Low self-efficacy (low self- } \\
\text { confidence, weak-minded, passivism) } \\
\text { - Competing priorities (too busy, too } \\
\text { many other problems, another } \\
\text { physical problem) } \\
\text { - Fatalism } \\
\text { gisinformation (lack of physician } \\
\text { guidance, lack of awareness, lack } \\
\text { of health information) }\end{array}$ \\
\hline $\begin{array}{c}\text { Social network } \\
\text { experiences }\end{array}$ & $\begin{array}{l}\text { - Advocacy (advice from husband, } \\
\text { family member and friends) } \\
\text { - Family history } \\
\text { - Mass media } \\
\text { - Appropriate models } \\
\text { - Medical recommendation }\end{array}$ & $\begin{array}{l}\text { - Ineffective health communication } \\
\text { (lack of medical recommendation, } \\
\text { lack of physician-patient relationship, } \\
\text { physician clinic crowded) }\end{array}$ \\
\hline $\begin{array}{l}\text { Accessibility of } \\
\text { services }\end{array}$ & $\begin{array}{l}\text { - Government and community } \\
\text { support (insurance, collective } \\
\text { screening, convenient location) }\end{array}$ & $\begin{array}{l}\text { - Governmental and community support } \\
\text { (cost, time barriers, transportation) }\end{array}$ \\
\hline
\end{tabular}

her role as a caregiver for herself or other family members: "I need to take care of myself, because no one can take care of me". Another participant responded: "My children depend on me".

One participant described an experience when she was seeking self-care services. She said "The doctor told me that when you turn 40, you should have a mammogram every year and I've been doing it ever since; I don't like to be told unexpectedly that I have cancer". The following statement by a participant clarifies this point that early detection is important to provide reassurance that they do not have cancer: "I wanted to know for sure if I was OK or not".
There were 3 main subcategories related to self-care. These were personal health, cancer history and life status. One participant commented: "If I knew that I had a tumour, I would get treatment". Another said: "I do not want to neglect myself", and another: "If something is related to my health and future, why not take care of it?" The women strongly emphasized the role of values and optimism in decision-making about screening. To them, spiritual values were one's belief in salvation. One woman said: "We have responsibility for our body; we should go to the doctor because it is a divine responsibility based on the divine teaching that humans should act and only 
then the help of God will come". Or "One relative had breast cancer, they took care of her and now she is cured, so I think cancer is controllable".

Attitudes, beliefs and feelings as barriers Participants' attitudes, beliefs and feelings emerged as barriers to seeking screening in 6 main themes: negligence, cancer-related fear, low self-efficacy, competing priorities, fatalism and misinformation.

Negligence was mainly characterized as carelessness. There were 3 main subcategories related to negligence; perception of good health, perception of not needing the test, and absence of symptoms. Many participants $(n=16)$ complained of the "lack of self-concern" in Iranian women. They implied that self-sacrifice is an important motive. According to this group of participants, lack of symptoms was a main reason for not having the test. One participant said: "Nothing is wrong with my breast" and another said: "I have never felt any pain". One of the participants said "From its name, we do not like this disease; we feel sad". Various misconceptions of good health were evident in participant's lack of awareness of risk. One of them said: "There is no need to go and search for and look around for it [breast cancer] because I am sure that I have a healthy body". Another one said: "When I feel that I don't have anything, why would I take precautions?"

Women considered fear as an important and critical factor in screening behaviour. They believed that when someone feels fear, it leads to a negative attitude toward prevention. There were 4 main subcategories: fear of cancer diagnosis, fear of pain, fear of radiation and fear of death.

Almost all the participants $(n=28)$ emphasized the role of self-efficacy in screening behaviour. To them, lowefficacy would result in self-doubt, causing the women to feel weak and powerless; so that women would avoid participating in cancer-detection programmes. There were 3 subcategories related to low self-efficacy: low self-confidence, weak-mindedness and passivism.

Cancer-related fatalism has been defined as the perception that individuals have limited influence to change the course of the disease, to detect it early or to prevent it. One of the participants said: "It depends on God's will that this disease will not affect us" or "I am not afraid, everything is in the hands of God". The greatest rate of fatalism was expressed by women of low educational status and housekeepers.

Among the most important competing priorities deterring women from screening included: too many other problems or worries, too busy and another physical problem.

Similarly, the importance of misinformation about screening - lack of physician guidance or referral, low health information and lack of awareness about the importance of breast cancer screening-was identified by a majority of the participants, even among educated women (with the exception of women working in the medical field). Sometimes misinformation increases fears, as indicated in these statements: "mammography may cause disfigurement" or "you must not have repeat mammography because of the effects of electricity".

\section{External factors}

External factors were grouped into 2 broad categories: women's social network experiences and accessibility of services. Social network experiences were defined as a participant's reliance on information about breast cancer screening obtained from relatives or friends, while accessibility of services was defined as those factors related 
to the availability of screening services to participants.

\section{Social network experiences as facilitating factors}

Some participants regarded their friends or family as a source of encouragement to seeking breast cancer screening. The concepts grounded under this category called advocacy, included advice from a family member (husband, children or sisters), advice from friends, and family history of breast cancer, knowing someone with cancer or knowledge about related health promotion programmes in the popular media, especially television health programmes. Regarding the influence of patientphysician communication, one of the participants said: "If they [doctors] tell me to seek screening, I will go". And regarding the influence of friends, one said: "Well, I was talking to a friend, and she told me since I was 40 I should get a mammogram, and ever since then I've gotten a yearly mammogram". Another participant thanked her friend because she advised her "not to neglect herself".

Regarding a family history of breast cancer, women considered their "feelings of obligation" as a prerequisite in health protection and also as an important factor for saving their lives. One woman said: "My aunt had cancer of the breast and as an obligation, I have to have the mammogram done every year". Women participants felt more confident in accepting as a role model the behaviour of someone who was in the same situation as they were. Many participants $(n=16)$ mentioned that "if they [cancerous women who had early detection and successful treatment] tell me to seek screening, I will go to do a mammogram because they are experienced".
Social network experiences as barriers

Social network experiences also emerged as a barrier to breast cancer screening, and ineffective health communication was an important factor affecting women's practices. There were 3 subcategories related to this: lack of effective physician-patient relationship, lack of medical recommendation and crowded physician's clinic. The participants emphasized that effective physician-patient communication is a prerequisite for increasing women's use of screening services and that physicians play a powerful role in motivating women to comply with breast cancer screening.

\section{Accessibility of services as facilitating \\ factors}

Good accessibility of services was seen as a facilitating factor for screening, under the general theme of government and community support. Issues related to this category included a women's insurance status, the availability of affordable screening services, particularly mass screening projects at the workplace, and having adequate transportation to screening sites. A few participants said: "We had a mammogram this year because our office [Ministry of Education] provided free mammogram services".

\section{Accessibility of services as barriers}

Problems with accessibility of services created barriers to screening, under the same theme of government and community support. Factors such as high cost, too busy [dual responsibility] and inadequate distribution of clinics were cited as barriers to breast cancer early detection. Participants mentioned that employed women have competing responsibilities (housekeeping and work outside the home), so they are unable to get to health services. A great majority of 
the employed women said: "We don't have any time, we couldn't travel, and it [the screening site] should be easy to get to".

\section{Discussion}

The findings of the current study indicate that 2 groups of internal and external variables can facilitate and/or inhibit the women's breast cancer screening behaviour. For instance, participants pointed out: "I know, if discovered early, it [breast cancer] could be treated.... and ... would prevent further deterioration". Such facilitating factors (beliefs), which are consistent with a preventive care paradigm, have been reported to be positively correlated with health outcomes in women with other chronic diseases [12].

According to the participants in the present research, the primary barriers to taking action on screening were competing concerns, such as taking time to care for their families, hectic daily schedules and "carelessness". Some participants mentioned that Iranian women will often delay visiting a physician until they are so sick that they are unable to attend to any other priority. As one participant put it "I don't go to the doctor unless I become completely disabled, and only then I would go". Montazeri confirmed that about $25 \%$ of patients with breast symptoms had a delay of more than 3 months before seeking help from a health professional [6].

A strong faith in God and in God's actions were observed as internal facilitating factors for the participants in this research. Bener et al., however, when studying women's screening behaviour in the United Arab Emirates, found that religious faith attenuated the women's fear and reduced the perceived threat of the disease [13]. As reported by other studies, fatalistic attitudes may lead to a lack of participation in cancer screening [14]. Faith as a facilitating factor can be encouraged and supported by the health care system if health promotion messages are tailored to appeal to the Muslim faith of Iranian women: "God wishes people to take responsibility for themselves" and "religious precepts (laws)".

Our results indicate that women with the highest level of cancer-related fatalism were housekeepers and less educated. As Partin and Slater mentioned, barriers to attending screening include negative experiences associated with previous mammograms, lack of physician referral, limited access to routine health care services, low perceived susceptibility to breast cancer, failure to find a mammogram reassuring, cost and logistic challenges [15]. Effective health communication has been found to be a very important motivation factor to screening behaviour [13]. In this respect, this research found that the physician's recommendation is an important factor in encouraging screening.

The role of participants' fear emerged variously as a facilitator or as a barrier in the context of screening behaviour. The construct called fear or worry remains the most extensively studied emotional variable. Currently, however, it is unclear whether fear acts as a barrier or a facilitator in screening behaviour. Women's fear surrounding breast cancer seems to encompass many factors but certainly includes fear of a cancer diagnosis, fear of embarrassment [16], fear of pain or discomfort and other complications [17]. To this list, we can add fear of the medical establishment, radiation and death. A belief that "it is better not to know" has been reported as a barrier to screening in studies of Hispanic women [18], but this was not found in our Iranian sample. 
The present research found that social networks are important because they serve as a source of advocacy and health information. Participants emphasized that spouse advocacy is one of the major facilitators to individual readiness to attend screening. And the role of their family (children/sister) and friends in preparing women to make effective decisions seems to have the greatest facilitator effect in this regard.

According to the participants in our research, self-confidence is considered a vital factor and Otero-Sabogal et al.'s findings confirm this assertion [19]. The effect of women's low self-efficacy in cancer prevention practices was also confirmed in studies by Miller [20].

\section{Conclusion}

This study helped us to clarify the effective factors in Iranian women's breast cancer screening behaviour. According to the par- ticipants, government and non-government health planners have the responsibility for the provision of public women's health care facilities, and screening must be considered the best choice for reducing mortality. However, at the present time, routine breast cancer screening has not been introduced into the health care system in the Islamic Republic of Iran.

\section{Acknowledgements}

We gratefully acknowledge the very helpful participation of the women, as well as the staff from MISAGH and ICBC without whose contribution this study would not have been completed. The findings reported in this article were extracted from the first author's $\mathrm{PhD}$ dissertation at the Department of Health Education of Tarbiat Modares University, therefore the official support of the University is also acknowledged.

\section{References}

1. International Agency for Research on Cancer. CANCERMondial [online database] (http://www-dep.iarc.fr/, accessed 7 December 2006).

2. Translating knowledge into action. INCTR Report. Brussels, International Network for Cancer Treatment and Research, 2005.

3. Summary report on cancer incidence in Iran. Tehran, Islamic Republic of Iran, Iranian Center for Prevention and Control of Disease, Ministry of Health and Medical Education, Treatment and Education, 2000.

4. Harirchi I et al. Breast cancer in Iran: results of a multi-center study. Asian pacific journal of cancer prevention, 2004, 5(1):24-7.

5. Sidoni $\mathrm{M}$ et al. Breast cancer in young women: clinicopathological features and biological specificity. Breast, 2003, 12:247-50.

6. Montazeri A et al. Delayed presentation in breast cancer: a study in Iranian women. BMC women's health, 2003, 3:4.

7. Shamsa AZ et al. National project for cancer registry: proposing a model by the National Center for Cancer Registry. Sponsored by the Cancer Institute of Tehran University of Medical Science. Tehran, Islamic Republic of Iran, Deputy of Research, Ministry of Health and Medical Education, Treatment and Education, 2002).

8. Ebrahimi $\mathrm{M}$ et al. Risk factors for breast cancer in Iran: a case-control study. Breast cancer research, 2002, 4:R10-3.

9. Harris JR, Morrow M, Osborne CK. Diseases of the breast, 2nd ed. Philadelphia, Lippincott Williams and Wilkins, 2002. 
10. Strauss A, Corbin J. Basics of qualitative research: grounded theory procedures and techniques. Newburg Park, California, Sage Publications, 1994.

11. Steubert HJ, Carpenter DR. Qualitative research in nursing: advancing the humanistic imperative, 3rd ed. New York, Lippincott, Williams and Wilkins, 2002.

12. Gbenga $O$ et al. Perceptions of barriers and facilitators of cancer early detection among low-income minority women in community health centers. Journal of the National Medical Association, 2005, 97(2):167-70.

13. Bener $A$ et al. The determinants of breast cancer screening behavior: a focus group study of women in the United Arab Emirates. Oncology nursing forum, 2002, 29(9):E91-8.

14. Powe BD, Weinrich S. An intervention to decrease cancer fatalism among rural elders. Oncology nursing forum, 1999, 26(3):583-8.

15. Partin MR, Slater JS. Promoting repeat mammography use: insights from a systematic needs assessment. Health education and behavior, 2003, 30 (1):97-112.
16. Andersen MR et al. Breast cancer worry and mammography use by women with and without a family history in a population-based sample. Cancer epidemiology, biomarkers and prevention, 2003, 12(4):314-20.

17. Montazeri A et al. Anxiety and depression in Iranian breast cancer patients before and after diagnosis. European journal of cancer care, 2000, 9(3):151-5.

18. Austin $L$ et al. Breast and cervical cancer screening in Hispanic women: a literature review using the health belief model. Women's health issues, 2002, 12:122-8.

19. Otero-Sabogal $R$ et al. Access and attitudinal factors related to breast and cervical cancer rescreening: why are Latinas still underscreened? Health education and behavior, 2003, 30:337-59.

20. Miller SM. Cognitive-social and biobehavioral research in cancer prevention and control. Fox Chase Cancer Center 2005 Scientific Report. Philadelphia, Fox Chase Cancer Center, 2005 (http://www. fccc.edu/docs/sci_report/Miller.pdf, accessed 4 December 2006). 